\title{
Health Behavior Knowledge and Self-efficacy as Predictors of Body Weight
}

\author{
Pouran Faghri* and Jennifer Buden
}

Department of Allied Health Sciences, University of Connecticut, Storrs, CT, USA

\begin{abstract}
Obesity is a public health concern with significant economic costs affecting employers. Worksite wellness programs benefit from developing tailored interventions that consider employees' health-related knowledge and self-efficacy to change behavior. Correction is a high stress occupation with elevated rates of overweight and obesity. Poor stress management and barriers to achieve optimal health in the work environment increases the need for adequate knowledge and self-efficacy, or the level of confidence to eat healthy and be physically active. This cross-sectional pilot study used a sample of sixteen correctional employees who participated in a Nutrition and Physical Activity Questionnaire. This survey assesses knowledge and self-efficacy for nutrition and physical activity and current health behaviors, such as current dietary habits and level of physical activity. Demographic and anthropometric data were also collected for statistical analyses. Participants were primarily male correction officers working first shift with a mean $\left( \pm\right.$ SE) BMI of $29( \pm 1.05) \mathrm{kg} / \mathrm{m}^{2}$, classified as overweight. Multiple regression analyses revealed that knowledge and self-efficacy scores predicted variation in BMI when controlling for other scores in the model. Findings from this study may be applicable for future health promotion interventions in high-risk occupations. In high-risk occupations such as corrections, understanding environmental and organizational barriers to achieving good health and reducing chronic disease risk is important. However, in addition to reducing these barriers, increasing knowledge, improving skills and self-efficacy to achieve good health are also critical in order to develop effective interventions for this population.
\end{abstract}

Keywords: Self-efficacy; Obesity; Stress management

\section{Introduction}

Obesity is a national epidemic in the United States that affects all levels of the population. Sixty-nine percent of adults over the age of 20 are overweight or obese according to data collected in 2011-2012 by the Centers for Disease Control and Prevention. Further, obesity rates continue to be a concern in children and adolescents [1]. Nutrition and exercise habits remain key components to promote healthy behaviors among all age groups.

Overweight and obesity have a multitude of consequences beyond increased risk for comorbidities, including economic, social, and societal costs. For workplaces with elevated rates of overweight and obesity, the associated higher rates of presenters, absenteeism and low productivity, have a significant economic impact on employers [2]. Several studies have identified positive relationships between obesity, absenteeism [3,4] and low productivity [5]. Furthermore, there is a positive association between job characteristics in a high stress, low control workplace, such as exposure to unpredictable situations during work hours or having a lack of control over job routines, and BMI [69]. Corrections officers have higher rates of overweight (40.7\%) and obesity $(43.3 \%)$ compared to national norms in the United States where $33.6 \%$ of adults are overweight and $34.9 \%$ are obese, respectively [10-13]. Evidence has shown that employees may cope with job stress by developing unhealthy behaviors such as decreased physical activity and unhealthy eating, which may contribute to cardiovascular disease and type II diabetes [14].

As employers are required to compensate for portions of rising healthcare costs, workplace wellness programs have become a feasible approach to improve health and wellness in the workplace. Benefits of these programs extend to both employees and employers. A metaanalysis on the return on investment from prevention and wellness programs in the workplace revealed that employers see significant savings from both medical costs and reduced absenteeism [15]. Beyond the immediate health benefits for employees, research shows that wellness programs also improve organizational morale and job satisfaction $[15,16]$. With the reported higher health care costs linked to overweight and obesity, workplace wellness programs have gained attraction in recent years as a cost savings approach. However, most employers institute a "one size fits all" approach rather than a tailored intervention that considers overweight and obese employees' knowledge, attitude and confidence to manage their body weight in a high stress work environment [17].

Numerous factors contribute to the obesity epidemic, including environment, genetics, socio-demographics, and cultural influences, such as knowledge and attitude [18]. Characteristics of the job may increase the need for adequate knowledge of healthy lifestyle behaviors that contribute to weight gain. For example, lack of access to healthy foods in the workplace and unique job stress may make it more challenging to engage in healthy behaviors if coping mechanisms and knowledge are inadequate. Understanding the relationships between knowledge, attitude and health behaviors related to dietary intake, physical activity and body weight could play an important role in developing intervention strategies targeting energy balance and reducing the prevalence of obesity.

The purpose of this pilot study was to investigate the relationships between obesity-related behaviors (diet, physical activity) and health

*Corresponding author: Pouran Faghri, Department of Allied Health Sciences University of Connecticut, Storrs, CT, USA, Tel: 860-486-0018; Fax: 860-486-5375 E-mail: pouran.faghri@uconn.edu

Received July 25, 2015; Accepted September 10, 2015; Published September 15,2015

Citation: Faghri P, Buden J (2015) Health Behavior Knowledge and Self-efficacy as Predictors of Body Weight. J Nutr Disorders Ther 5: 169. doi:10.4172/2161 0509.1000169

Copyright: $(2015$ Faghri $P$, et al. This is an open-access article distributed under the terms of the Creative Commons Attribution License, which permits unrestricted use, distribution, and reproduction in any medium, provided the original author and source are credited. 
behavior knowledge and attitudes (self-efficacy for eating and exercise) in employees working in a high stress occupation. We hypothesize that there is a negative relationship between nutrition and physical activity knowledge, self-efficacy and BMI. Those with less knowledge and selfefficacy scores will have higher BMI.

This information may help identify knowledge and attitude barriers to physical activity and healthy eating at the workplace and aid in developing tailored educational materials and interventions for overweight and obese employees.

\section{Methods}

\section{Study design}

This was a cross-sectional study of a survey called the Nutrition and Physical Activity Questionnaire (NPAQ) [19] completed by a group of correctional employees.

\section{Measurements}

Nutrition and physical activity questionnaire: The NPAQ developed by Faghri et al. [19] consists of 67 multiple-choice items divided into four sections and takes approximately 35-40 minutes to complete. Higher sum scores within each domain are indicative of greater knowledge, self-efficacy and healthier behaviors. Section I, Nutrition Knowledge, contains 49 multiple-choices items to assess understanding of cholesterol, fat, fiber, sodium and protein in the diet as well as knowledge of dietary guidelines, Nutrition Facts label reading, and weight management. Items are true/false, application, or best choice questions. Each question is valued at one point for a correct answer and zero points for incorrect answers. The total possible score is 97. Questions were adapted from Hawkes et al., Parmenter et al., Fielder, and Mackison et al. [20-23]. Section II, Eating Assessment, contains 8 multiple-choice items to assess average intake of fruits, vegetables, whole grains and low-fat dairy products. Respondents can obtain up to 3 points per item, where a score of 0 points for an item indicates being not at all healthy and a score of 3 points indicates being mostly healthy/extremely healthy. Questions were adapted from Fielder [22] and the total possible score is 24 .

Section III, Physical Activity Knowledge and Physical Activity Assessment, contains 6 multiple-choice items to assess understanding of activity guidelines to obtain health benefits. Each question is valued at one point for a correct answer, with a total possible score of 6 . Two additional items assess self-reported frequency and type of physical activity over the past week (mild, moderate and vigorous) for at least 30 minutes per day. Questions were adapted from Steptoe et al., Morrow et al., and Washburn et al. [24-26]. Section IV, Self-efficacy, contains 8 items to measure exercise self-efficacy (ESE) and 12 items to measure weight loss self-efficacy (WLSE). Questions for this domain follow a Likert scale ranging from "Not Confident" ( 1 point) to "Very Confident" to "I already do this" (5 points). The total possible score for ESE is 40, and for WLSE is 60. Questions were adapted from Sallis et al. [27]. Sum scores from each domain were used to create new observed variables for statistical analyses.

Demographic information: Age, gender, race/ethnicity, level of education, job title at DOC, shift, years worked at DOC, income, reported hours of voluntary overtime worked and reported hours of mandatory overtime worked were also collected. A Registered Dietitian Nutritionist and Research Assistants assessed height and weight during survey distribution to calculate BMI (in $\mathrm{kg} / \mathrm{m}^{2}$ ) and waist circumference (in $\mathrm{cm}$ )

\section{Study population}

Sixteen correctional employees from one correctional institution completed the NPAQ.

\section{Statistical analyses}

Data was analyzed using IBM SPSS ${ }^{\mathrm{TM}}$ software version 21 for descriptive analysis and SAS version 9.3 for advanced statistical analyses. The primary variables analyzed include BMI $\left(\mathrm{kg} / \mathrm{m}^{2}\right)$, waist circumference $(\mathrm{cm})$, age (years), job classification, gender, and assessment scores from the NPAQ. New variables were computed using sum scores from each domain in the NPAQ. Descriptive statistics were run on demographic variables and sum scores to obtain measures of central tendency (mean, standard deviation, median) and frequency distributions. Normality was assessed using histograms and numerical tests to evaluate $p$ values. Prior to running individual inference tests, the appropriate test assumptions were run. ANOVAs and regressions were run to evaluate statistical significance among sum scores for dependent variables (gender, BMI, job position). Further, post hoc testing was performed to identify where significance lies, when necessary. Cut-offs for significance were set at $\mathrm{p}<0.05$.

\section{Results}

\section{Descriptive statistics}

The majority of participants were overweight, with a mean [standard error (SE)] BMI of $29.03 \mathrm{~kg} / \mathrm{m}^{2}$ (1.05) and waist circumference of $97 \mathrm{~cm}$ (3.93), measured at the time the survey was distributed. Participants were primarily male (68.75\%), and had a mean age of 42 . Mean scores for nutrition knowledge and physical activity knowledge were 56.125 and 4.687, respectively. Mean scores for weight loss selfefficacy and exercise self-efficacy were 42.437 and 28.812, respectively. The majority of participants classified themselves as being White, European descent (50\%) and had an average education attainment of some college (40\%). Distribution of respondents' job class included, $75 \%$ Correction Officers (CO's), 12.5\% Lieutenants, and 12.5\% Support Staff (maintenance, food service, admin staff, teacher, chaplain). The majority of participants worked at the Department of Corrections (DOC) for 6-10 years (50\%), and worked on first shift (62.5\%). (Table 1) provides further anthropometric and demographic information.

A moderate negative skew for physical activity knowledge score was noted. All other scores assessing knowledge and self-efficacy were normally distributed (nutrition knowledge, eating assessment score, exercise self-efficacy, and weight loss self-efficacy).

Simple linear regressions to evaluate knowledge and self-efficacy scores as predictors of BMI revealed no significance, indicating that these scores independently do not predict BMI (Table 2). However, further analysis using multiple linear regression revealed that $58 \%$ of the variance in BMI could be accounted for by knowledge (nutrition, physical activity) and self-efficacy scores (ESE, WLSE) $(\mathrm{p}=0.035)$. The adjusted R-squared for this model indicated that $43 \%$ of the variance in BMI was predicted by these variables. Evaluation of the coefficients indicated that for every unit increase in physical activity knowledge score, BMI would decrease by 3.58, when controlling for the other variables in the model $(p=0.05)$. For every unit increase in WLSE, there would be an expected 0.39 decrease in BMI, when controlling for the other variables $(\mathrm{p}=0.008)$. To provide better interpretation of the strength of these outcomes, standardized beta coefficients were run for the variables within the model. Weight loss self-efficacy had the highest standardized coefficient $(-0.694)$ and one could infer that a 


\begin{tabular}{|c|c|c|}
\hline \multirow{2}{*}{ Gender } & Male & $68.75 \%(n=11)$ \\
\hline & Female & $31.25 \%(n=5)$ \\
\hline Age & Years $\pm S D$ & $42.06 \pm 8.94$ \\
\hline \multirow{6}{*}{ Anthropometrics } & Weight: pounds \pm SE & $194.64 \pm 10.29$ \\
\hline & BMI: $\mathrm{kg} / \mathrm{m}^{2} \pm \mathrm{SE}$ & $29.02 \pm 1.05$ \\
\hline & BMI (males): $\mathrm{kg} / \mathrm{m}^{2} \pm \mathrm{SE}$ & $30.24 \pm 1.02$ \\
\hline & BMI (females): $\mathrm{kg} / \mathrm{m}^{2} \pm \mathrm{SE}$ & $26.34 \pm 2.20$ \\
\hline & Waist Circumference (males): $\mathrm{cm} \pm \mathrm{SE}$ & $104.9 \pm 2.14$ \\
\hline & Waist Circumference (females): $\mathrm{cm} \pm \mathrm{SE}$ & $81.4 \pm 2.83$ \\
\hline \multirow{6}{*}{ Race } & White, European Descent & $50 \%$ \\
\hline & Black, African American, African & $25 \%$ \\
\hline & American Indian, Alaska Native & $0 \%$ \\
\hline & $\begin{array}{l}\text { Asian, Asian American (includes Filipino, } \\
\text { Korean, Chinese) }\end{array}$ & $0 \%$ \\
\hline & Other & $18.75 \%$ \\
\hline & $\begin{array}{l}\text { Latino or of Hispanic Origin or Descent } \\
\text { (answered yes includes: Puerto Rican, Cuban } \\
\text { American, Mexican American, etc.) }\end{array}$ & $18.75 \%$ \\
\hline \multirow{5}{*}{ Education } & Less than high school & $6.67 \%$ \\
\hline & High School Graduate or GED & $26.67 \%$ \\
\hline & Some College & $40.00 \%$ \\
\hline & College Degree (2 or 4 year) & $26.67 \%$ \\
\hline & Graduate Degree & $0 \%$ \\
\hline \multirow{3}{*}{ Job Class } & CO, CTO, Counselor (frontline staff) & $75 \%$ \\
\hline & $\begin{array}{l}\text { Lieutenant, Captain, Deputy Warden, Warden, } \\
\text { Supervisors }\end{array}$ & $12.5 \%$ \\
\hline & Support Staff, Medical Staff & $12.5 \%$ \\
\hline \multirow{5}{*}{ Years at DOC } & $0-5$ years & $12.5 \%$ \\
\hline & $6-10$ years & $50 \%$ \\
\hline & $11-15$ years & $12.5 \%$ \\
\hline & $16-20$ years & $12.5 \%$ \\
\hline & 20 or more years & $12.5 \%$ \\
\hline \multirow{3}{*}{ Shift } & First & $62.5 \%$ \\
\hline & Second & $31.25 \%$ \\
\hline & Third & $6.25 \%$ \\
\hline
\end{tabular}

Table 1: Anthropometrics and demographics of study participants.

one standard deviation decrease in WLSE would yield a 0.694 standard deviation predicted increase in BMI (Table 3).

\section{Discussion}

This pilot study provides strong findings related to the associations between BMI, health behaviors and the influence of knowledge and self-efficacy surrounding obesity in a high stress occupation such as corrections. Unhealthy lifestyle behaviors contribute to obesity risk. Having knowledge and skills to engage in healthy behaviors raises confidence to overcome barriers and increases perceived benefits to change behavior. Despite the growth of worksite health promotion, corrections remains an occupation of concern due to high obesity rates, high levels of stress, and lack of job control that indirectly influence lifestyle behaviors $[28,29]$. Social Cognitive Theory (SCT) proposes there is a relationship between knowledge, attitude, and skills, which translates into action or behavior by raising confidence to overcome barriers. Previous health promotion research has used SCT as a model for evaluating the relationship between knowledge, self-efficacy, and health behavior [30].

A previous study in corrections reported that employees with higher levels of obesity (BMI) had lower self-efficacy to engage in healthy behaviors [10]. Associations between social-cognitive variables, health behaviors and outcomes have also been reported [31,32]. However, no previous research has evaluated knowledge or self-efficacy as predictors of current health behavior (dietary habits, level of physical activity) or weight status. In addition, little research has evaluated the interaction effect between knowledge and self-efficacy on weight status. The results from this cross-sectional analysis provided significant findings to better understand the corrections population, a group at high-risk for obesity and its' associated comorbidities. From multiple regression analyses, we can conclude that some cognitive scores are associated with BMI in corrections employees. Our model indicated that both physical activity knowledge and weight loss self-efficacy are associated with BMI, when controlling for other factors. However, violations of some regression assumptions indicate we must be cautious making conclusions about these results. In addition, because this was only a cross-sectional analysis, we can only infer that these cognitive variables are associated, and we are unable to predict a causal relationship. Future research should use a larger sample size to test statistical assumptions and evaluate generalizability of results.

A quasi-experimental weight loss intervention using a participatory design used a modified version of the NPAQ. They administered the survey at baseline and 20 weeks to measure change in knowledge and self-efficacy for nutrition, physical activity, and dietary habits. When controlling for gender and age, some change in body weight and waist circumference were explained by nutrition knowledge and exercise self-efficacy. This study suggests that improving knowledge and selfefficacy would influence the effectiveness of an intervention in the worksite setting [11]. Similar studies have evaluated knowledge and self-efficacy to predict participation in a worksite health promotion program, and suggest that individuals with lower knowledge or selfefficacy are less likely to participate or adhere to interventions [33-35].

Despite that some significant results were identified; this study is limited by its small sample size. Future implications of this research include: 1) evaluation of these measures with a larger sample size to better understand this population and 2) development of tailored

\begin{tabular}{|c|c|c|c|c|}
\hline \multicolumn{5}{|c|}{ Dependent Variable $=B M I$} \\
\hline Independent Variable & R-squared & Regression Coefficient & p value & $\begin{array}{l}\text { Interpretation } \\
\text { (i.e., could be inferred if there was a significant } p \text { value) }\end{array}$ \\
\hline Nutrition Knowledge & 0.1389 & -0.17495 & 0.1551 & $\begin{array}{c}\text { For a one unit increase in nutrition knowledge, we would see } \\
\text { approximately a } 0.2 \text { decrease in BMI }\end{array}$ \\
\hline Physical Activity Knowledge & 0.0943 & -1.62914 & 0.2473 & $\begin{array}{c}\text { For a one unit increase in PA knowledge, we would see } \\
\text { approximately a } 1.6 \text { decrease in BMI }\end{array}$ \\
\hline Eating Assessment & 0.0043 & -0.06361 & 0.8089 & $\begin{array}{l}\text { For a one unit increase in eating assessment score (indicating } \\
\text { healthy eating), we would see a } 0.06 \text { decrease in BMI }\end{array}$ \\
\hline Exercise Self-efficacy (ESE) & 0.0039 & 0.06701 & 0.8176 & For a one unit increase in ESE, we would see a 0.06 increase in BMI \\
\hline $\begin{array}{l}\text { Weight Loss Self-efficacy } \\
\text { (WLSE) }\end{array}$ & 0.1457 & -0.21645 & 0.1446 & $\begin{array}{c}\text { For a one unit increase in WLSE, we would see a } 0.2 \text { decrease in } \\
\text { BMI }\end{array}$ \\
\hline
\end{tabular}

Table 2: Knowledge and self-efficacy scores did not independently predict BMI using simple linear regression. However, relationships revealed by regression coefficients provide relevant interpretations. 
Citation: Faghri P, Buden J (2015) Health Behavior Knowledge and Self-efficacy as Predictors of Body Weight. J Nutr Disorders Ther 5: 169. doi:10.4172/2161-0509.1000169

Page 4 of 5

\begin{tabular}{|c|c|c|c|c|c|c|}
\hline \multicolumn{4}{|c|}{ Dependent Variable $=B M I$} & \multicolumn{3}{|c|}{ Parameter Estimates } \\
\hline Model \# & $\begin{array}{l}\text { Independent Variables } \\
\text { (i.e., predictors) }\end{array}$ & R-squared & $\begin{array}{l}\text { Model } \\
\text { p value }\end{array}$ & $\begin{array}{l}\text { Regression } \\
\text { Coefficients }\end{array}$ & $p$ values & $\begin{array}{c}\text { Standardized } \beta \\
\text { Coefficient }\end{array}$ \\
\hline 1 & Nutrition \& Physical Activity Knowledge & 0.1919 & 0.2503 & & & \\
\hline 2 & Nutrition Knowledge \& Eating Assessment & 0.1403 & 0.3743 & & & \\
\hline 3 & Eating Assessment \& WLSE & 0.1497 & 0.3485 & & & \\
\hline 4 & ESE \& WLSE & 0.1564 & 0.3310 & & & \\
\hline 5 & Physical Activity Knowledge \& ESE & 0.1291 & 0.4071 & & & \\
\hline \multirow{4}{*}{6} & Nutrition Knowledge & \multirow{4}{*}{0.5806} & \multirow{4}{*}{0.0352} & -0.1564 & 0.1608 & -0.3332 \\
\hline & Physical Activity Knowledge & & & -3.5838 & 0.0543 & -0.6755 \\
\hline & ESE & & & -0.2727 & 0.4012 & -0.2551 \\
\hline & WLSE & & & -0.3936 & 0.0088 & -0.6941 \\
\hline
\end{tabular}

Table 3: Knowledge and self-efficacy scores predict BMI when controlling for other factors using multiple linear regression (several models tested).

interventions incorporating nutrition and physical activity knowledge and health behavior attitude and self-efficacy to aid sustainable behavior change.

\section{Conclusion}

Chronic diseases remain a national public health concern, and the worksite environment is an appropriate setting to provide tailored interventions by targeting multiple levels that influence lifestyle behaviors. Dietary habits and level of activity mediate chronic disease risk by aiding in weight management. Correctional employees may face additional barriers to engage in healthy lifestyle behaviors that mitigate chronic disease risk. Rotating shifts, understaffing, high levels of stress, low job control, work-family conflict, and other work culture factors may reduce an individuals' motivation to engage in healthy behaviors. This research is significant because it assesses health behavior constructs that contribute to level of obesity in a high-risk population. Socialcognitive variables such as knowledge and self-efficacy are critical in planning interventions to develop effective health promotion strategies that have the greatest impact. Future research should evaluate these variables with a larger sample size and perform advanced statistical analyses using structural equation modeling to look at cognitive scores and behavior as predictors of body weight.

\section{Acknowledgement}

This project was supported by a grant (1U19 OH008857) through the Center for the Promotion of Health in the New England Workplace, a National Institute for Occupational Safety and Health funded national work life center.

\section{References}

1. CDC/National Center for Health Statistics (2015) Diet/nutrition. Centers for Disease Control and Prevention Web site.

2. Hammond RA, Levine R (2010) The economic impact of obesity in the united states. Diabetes Metab Syndr Obes 3: 285-295.

3. Aldana SG, Pronk NP (2001) Health promotion programs, modifiable health risks, and employee absenteeism. J Occup Environ Med 43: 36-46.

4. Bungum T, Satterwhite M, Jackson AW, Morrow JR Jr (2003) The relationship of body mass index, medical costs, and job absenteeism. Am J Health Behav 27: 456-462.

5. Burton WN, Conti DJ, Chen CY, Schultz AB, Edington DW (1999) The role of health risk factors and disease on worker productivity. J Occup Environ Med 41: 863-877.

6. Hellerstedt WL, Jeffery RW (1997) The association of job strain and health behaviours in men and women. Int J Epidemiol 26: 575-583.

7. Martikainen PT, Marmot MG (1999) Socioeconomic differences in weight gain and determinants and consequences of coronary risk factors. Am J Clin Nutr 69: 719-726.

8. Netterstrom B, Kristensen TS, Damsgaard MT, Olsen O, Sjol A (1991) Job strain and cardiovascular risk factors: A cross sectional study of employed danish men and women. $\mathrm{Br} \mathrm{J}$ Ind Med 48: 684-689.

9. Ostry AS, Radi S, Louie AM, LaMontagne AD (2006) Psychosocial and other working conditions in relation to body mass index in a representative sample of australian workers. BMC Public Health 6: 53.

10. Morse T, Dussetschleger J, Warren N, Cherniack M (2011) Talking about health: Correction employees' assessments of obstacles to healthy living. J Occup Environ Med 53: 1037-1045.

11. Ferraro L, Faghri PD, Henning R, Cherniack M, Center for the Promotion of Health in the New England Workplace Team (2013) Workplace-based participatory approach to weight loss for correctional employees. J Occup Environ Med 55: 147-155.

12. Cheek F, Howard R (1984) Stress management for correctional officers and their families. NCJRS 119 .

13. Ogden CL, Carroll MD, Kit BK, Flegal KM (2014) Prevalence of childhood and adult obesity in the united states, 2011-2012. JAMA 311: 806-814.

14. Krajnak KM (2014) Potential contribution of work-related psychosocial stress to the development of cardiovascular disease and type II diabetes: A brief review. Environ Health Insights 8: 41-45.

15. Baicker K, Cutler D, Song Z (2010) Workplace wellness programs can generate savings. Health Aff (Millwood) 29: 304-311.

16. Parks KM, Steelman LA (2008) Organizational wellness programs: A metaanalysis. J Occup Health Psychol 13: 58-68.

17. Schroer S, Haupt J, Pieper C (2014) Evidence-based lifestyle interventions in the workplace--an overview. Occup Med (Lond) 64: 8-12.

18. Wyatt SB, Winters KP, Dubbert PM (2006) Overweight and obesity: Prevalence, consequences, and causes of a growing public health problem. Am J Med Sci 331: 166-174.

19. Faghri PD, Duffy VB, Benson NR, Cherniack MG (2012) Worksite weight loss intervention for employees in stressful workplaces: A pilot study and baseline survey indicators of success. DigitalCommons@UConn 2: 121

20. Hawkes A, Nowak M (1998) A validated nutrition knowledge questionnaire for cardiac patients. Australian Journal of Nutrition and Dietetics 55: 21-24.

21. Parmenter K, Wardle J (1999) Development of a general nutrition knowledge questionnaire for adults. Eur J Clin Nutr 53: 298-308.

22. Fielder CR (2008) Knowledge, motivations and behaviors regarding eating a healthy diet and physical activity in relation to self-esteem in college students. Texas University.

23. Mackison D, Wrieden WL, Anderson AS (2010) Validity and reliability testing of a short questionnaire developed to assess consumers' use, understanding and perception of food labels. Eur J Clin Nutr 64: 210-217.

24. Steptoe A, Pollard TM, Wardle J (1995) Development of a measure of the motives underlying the selection of food: The food choice questionnaire. Appetite 25: 267-284.

25. Morrow JR Jr, Krzewinski-Malone JA, Jackson AW, Bungum TJ, FitzGerald SJ (2004) American adults' knowledge of exercise recommendations. Res $Q$ Exerc Sport 75: 231-237.

26. Washburn RA, Montoye HJ (1986) The assessment of physical activity by questionnaire. Am J Epidemiol 123: 563-576. 
Citation: Faghri P, Buden J (2015) Health Behavior Knowledge and Self-efficacy as Predictors of Body Weight. J Nutr Disorders Ther 5: 169. doi:10.4172/2161- 0509.1000169

27. Sallis JF, Pinski RB, Grossman RM, Patterson TL, Nader PR (1988) The development of self-efficacy scales for health related diet and exercise behaviors. Health Education Research 3: 283-292.

28. Faghri PD, Mignano C, Cherniack M, Huedo-Medina TB (2015) Psychological health and overweight and obesity among high stressed work environments. Obesity: Open Access 1: 1-9.

29. Mignano C, Faghri PD, Huedo-Medina T, Cherniack M (2015) Predictors of health behaviors and body mass index (BMI) using a newly proposed emotionhealth behavior-weight (EBW) model.

30. Bandura A (2004) Health promotion by social cognitive means. Health Educ Behav 31: 143-164.

31. Sassen B, Kok G, Schaalma H, Kiers H, Vanhees L (2010) Cardiovascular risk profile: Cross-sectional analysis of motivational determinants, physical fitness and physical activity. BMC Public Health 10: 592.

32. Deitz D, Cook RF, Hersch RK, Leaf S (2014) Heart healthy online: An innovative approach to risk reduction in the workplace. J Occup Environ Med 56: 547-553.

33. Andersen LL (2011) Influence of psychosocial work environment on adherence to workplace exercise. J Occup Environ Med 53: 182-184.

34. Hunt MK, Stoddard AM, Kaphingst KA, Sorensen G (2007) Characteristics of participants in a cancer prevention intervention designed for multiethnic workers in small manufacturing worksites. Am J Health Promot 22: 33-37.

35. Abraham JM, Feldman R, Nyman JA, Barleen N (2011) What factors influence participation in an exercise-focused, employer-based wellness program? Inquiry 48: 221-241. 